\title{
Sosa on Epistemic Value: A Kantian Obstacle
}

Abstract: In recent work, Sosa proposes a comprehensive account of epistemic valuebased on an axiology for attempts. According to this axiology, an attempt is better if it succeeds, better still if it is apt (i.e., succeeds through competence), and best if it is fully apt, (i.e., guided to aptness by apt beliefs that it would be apt). Beliefs are understood as attempts aiming at the truth. Thus, a belief is better if true, better still if apt, and best if fully apt. I raise a Kantian obstacle for Sosa's account, arguing that the quality or worth of an attempt is independent of whether it succeeds. In particular, an attempt can be fully worthy despite being a failure. I then consider whether Sosa's competence-theoretic framework provides the resources for an axiology of attempts that does not place so much weight on success. I discuss the most promising candidate, an axiology grounded in the competence of attempts, or what Sosa calls adroitness. An adroit attempt may fail. I raise doubts about whether an adroitness-based axiology can provide a plausible explanation of the worthiness of subjects' beliefs in epistemically unfortunate situations, such as the beliefs of the brain in a vat. I conclude by speculating that the notion of a belief's fit with what the subject has to go on, a notion missing from Sosa's competencetheoretic framework, is crucial to explaining epistemic worth.

True belief is better than false belief. Knowledge is better than mere true belief. Knowledge is better than mere justified true belief. Such claims are familiar from the literature on epistemic value. Ernest Sosa has developed a simple but comprehensive account of epistemic value that explains these claims. Crucial to his account is an axiology of performances, a category he argues includes beliefs. One of the theoretical virtues of his account is its generality: it applies in the first instance to performances in general, and to beliefs insofar as they are performances.

Despite its attractiveness, I argue that Sosa's account is problematic. Powerful Kantian intuitions undermine his general performance axiology. A final section examines whether within the confines of Sosa's general competencetheoretic framework alternative performance axiologies are available which avoid this Kantian obstacle.

\section{Sosa's Performance Axiology and its Application to Beliefs}

Sosa's account of epistemic value is two-pronged. He proposes a general axiology for performances, and then claims about epistemic value fall out as a special case. follows:

Sosa's proposes a number of axiological principles, which I formulate as

Any performance, conceived of as an attempt with an aim, is (AX1): better to the extent that it attains in its aim.

(AX2): better still to the extent that it attains its aim aptly (i.e., through competence to attain that end). 
(AX3): and better still and best to the extent that it is guided to aptness by an apt belief that it would be apt, i.e., to the extent that it is fully apt. ${ }^{1}$

To justify these principles, Sosa appeals to examples. A hunter's performance is better if her shot reaches its target. It is better still if it reaches the target through her competence, i.e., if it is apt. But this is not what makes a performance best. In hunting, it matters where and when you take your shot, and how comparatively likely your shot would meet with success. If a hunter aptly hits her target but was guided by an unjustified belief about likely success, or no belief about likely success, we could appropriately criticize her. In criticizing her, Sosa sees us as finding flaws in her performance. If her performance is fully apt, there are no such flaws to find: the performance is flawless. ${ }^{2}$

For Sosa, beliefs are performances, attempts with aims. A belief aims at the truth (correct representation) and so is better if true (by AX1). A belief is better still if it aptly attains the truth (by AX2). A belief is better still and indeed best (by AX3) if it is knowledge full well, i.e., if it is fully apt belief, belief guided to aptness by an apt belief that one will (likely enough) aptly attain the truth in so believing.

This is the simple but comprehensive account.

\section{A Kantian obstacle}

In his review of Sosa's Knowing Full Well, E. J. Coffman (2013) considers a case in which, unbeknownst to an archer, a repulsive magnet is near the target. Although the magnet happened to be inoperative and did not interfere with the trajectory of the archer's arrow, it could easily have been operative, in which case it would have interfered. In Coffman's view, the archer's shot, guided to aptness as it is by a true belief that fails to be apt, seems no less worthy than it would have been had the belief been apt. Thus, he concludes that full aptness is not necessary for flawless performance.

In Coffman's case, a performance seems flawless despite being guided to aptness by a mere justified true belief. There are other cases in which the performance is flawless but the guiding belief is not even justified. To use an example from Kurt Sylvan cited by Sosa, consider a saxophonist with strong but misleading evidence that she is unable play a certain difficult piece competently

${ }^{1}$ Sosa $(2015,85)$ writes: "The fully desirable status for performances in general is full aptness."

${ }^{2}$ Qualifications are required to accommodate the distinct sorts of assessments we would like to make, for instance, of the basketball player who aims to miss the basket during a game. Here it is useful to introduce perspectives. From the perspective of the player's own desires, a miss might be better than the attempt is better if it is a miss. However, from the perspective of basketball, the attempt is worse if the player misses. An agent's attempts, when engaging in a practice, are evaluable with respect to the aims of the practice. The same goes for activityirrelevant goals, such as impressing your romantic interest with a flashy but risky shot (cf. Sosa 2015, 169). 
enough, who nevertheless ignores this evidence and plays the piece anyway, guided by her unjustified (but true) confidence that she can play it competently enough. Suppose she gives a spectacular performance manifesting her superior competence. Her performance seems just as good as than it would have been had she known all would work out well (Sosa 2015, 123-4), i.e., if the guiding belief was apt. ${ }^{3}$

Sosa presents materials for a reply to objections like this. He distinguishes attempts from deeds $(2015,124-5)$. Attempts are individuated in terms of choice and intention. Deeds are attributable doings. All attempts count as deeds, but not vice versa, because many attributable doings are not individuated in terms of choice and intention. Consider the deed of sinking a basket. Choice and intention do not enter into its individuation. This very same deed, the claim is, could have resulted from a different choice or no choice at all. Because deeds such as sinking a basket do not constitutively involve choice or intention, they are not improved by factors that improve the choice or intention, factors such as guidance by an apt belief about likely apt success. Sosa suggests that if we are careful in considering the above examples to focus on the attempt involved and not on the salient deeds involved that do not constitutively involve choice/intention, our intuitions will align with his axiological principles AX1-3.

Sosa means to limit his axiological principles AX1-3 to attempts, and so let us put aside axiological questions about deeds in general. Attempts, for Sosa, are intentional carry-throughs on choices or decisions $(2015,86)$. A fault with either the choice or the carry-through is a fault with the attempt. I agree with Sosa that a shot, conceived as a deed, could be of the highest quality even if the attempt, understood in his way, is of low quality. Perhaps a basketball player shouldn't have attempted a shot, because she was aware that she could have easily taken a less risky shot which, if successful, would have secured victory all the same. The shot considered as a deed of sinking a basket was flawless; not so, the attempt, considered as the intentional follow-through on a choice.

Ordinary language is not a reliable guide here. It seems peculiar to call the poorly selected but masterfully executed shot a poor attempt. Suppose a basketball player has a clear opportunity to take the easy shot which would win the game but takes a harder shot instead, sinking it. I doubt anyone would say, "bad try!" or "what sort of lame attempt is that?" Still, I agree with Sosa that the player's shot selection deserves criticism. And, in a case in which shot a player's intentional carry-through occurs over a period of time after the shot selection, the carry-through may well deserve criticism even if the original selection was praiseworthy. Consider an example from American football. A quarterback might select a play wisely, but as the opposing team lines up, it might become obvious that he should abandon the selected play. If he persists and attains success, the coach and fans might rightly criticize the follow-through. They might say "he should have changed the play call." So, even if Sosa's use of the term 'attempt' doesn't mesh well with the ordinary one,

${ }^{3}$ See Sylvan (forthcoming) for further discussion. 
it does refer to something real, and something that may be criticizable even if the agent attains the desired end. ${ }^{4}$

So far, Sosa seems to have a good answer to Coffman and Sylvan's proposed counterexamples. But I want to consider another kind of proposed counterexample, one that is squarely about attempts in Sosa's sense rather than mere deeds. The examples raise questions about the relation between the quality of an attempt and its success or failure.

Suppose LeBron James takes a three-point shot, in a situation in which such a shot makes sense given the state of the game. We might well praise the attempt as superb despite the fact that the ball turns out to collide midair with a bird which unaccountably appeared over the court. The shot selection was impeccable. The intentional follow-through on that selection, too, was ideal, based as it was on excellent judgment about the state of the game since selecting that shot. If the performance is the attempt, and the attempt is the intentional follow-through on shot selection, it seems this performance is unimpeachable - as good as it gets, and as good as it would have been if no bird had interfered and the attempt had been fully apt. ${ }^{5}$

We can easily construct similar examples for tennis players, archers, musicians, etc. An unpredictable gust of wind can spoil the success of a fine attempt in tennis or archery; a room with poor acoustics can spoil the success of a pianist's attempt at a clean trill; and so on. In each case, intuitively the attempt - as intentional follow-through on a choice - seems flawless, of just as high a quality as it would have been had there been no interference.

These points are reminiscent of a familiar Kantian intuition in ethics. In one of the most memorable passages in the Groundwork, Kant writes:

"The good will is good not through what it effects or accomplishes, not through its efficacy for attaining any intended end, but only through its willing, i.e., good in itself...

4 Sosa's account of epistemic value, of course, requires that beliefs be attempts. But could beliefs really be intentional carry-throughs on choices? This seems to imply that beliefs reside in the will, a surprising implication. Sosa claims that some beliefs are dispositions to judge, where judging is an intentional action. Beliefs, he thinks, inherit the agential status of their manifestations. They do reside in the will $(2015$, 210). Even functional beliefs, he argues, are rightly seen as aimed at ends, and so as action-like. These are provocative, controversial claims, but here I will not challenge them. For critical discussion of these claims, see McGrath (2017).

${ }^{5}$ What about the shot itself? There may be dispute about whether it's true to say that it was a great shot. I do find this intuitive. Other cases make it clearer. We're playing golf. Your son, aged 6, is with us. You putt the ball 25 feet. Just as it is about to fall into the hole, your son kicks it away. It seems to me that the shot is no worse for the child's interference. It doesn't succeed, but it is as admirable as a shot from that distance could be. (This is not to deny that some features of a shot do matter to its quality. If we vary the case and suppose that as LeBron James begins to shoot a sudden muscle twitch alters his movement, launching the ball to an unwanted height, then whether the shot happens to go in or not, it is not a shot of high quality.) 
Even if through the peculiar disfavor of fate, or through the meager endowment of a stepmotherly nature, this will were entirely lacking in the resources to carry out its aim, if with its greatest effort nothing of it were accomplished, and only the good will were left over (to be sure, not a mere wish, but as the summoning up of all the means insofar as they are in our control): then it would shine like a jewel for itself, as something that has its full worth in itself. Utility or fruitlessness can neither add to nor subtract anything from this worth. It would be only the setting, as it were, to make it easier to handle in common traffic, or to draw the attention of those who are still not sufficiently connoisseurs, but not to recommend it to connoisseurs and determine its worth." (AK4 394)

Actions which express this good will have moral worth. Like the good will itself, their worth does not come from their accomplishments. They can have maximal moral worth even if they fail to accomplish their aims.

Two people, in different parts of a seacoast, rush to rescue drowning children. Both intend to save the child they see drowning only for the child's sake, and both select the same course of action for doing so. The only difference is that in the one case the child swallows a large amount of water right as the rescuer reaches the child, whereas in the other this doesn't happen, and so in one case the rescuer saves the child but in the other she doesn't. Intuitively, the two rescuers' actions certainly their Sosa-style attempts - are equally worthy, even though one is fully apt and the other unsuccessful. (To ensure that the lucky rescuer's action counts as fully apt, let us add that the saved child couldn't easily have swallowed the water before the rescuer arrived, because this child's reflex (unlike the other child's) is to clamp his mouth closed in crisis moments and hold it that way.)

In these cases, moral worthiness is at issue. But worthiness is not limited to the moral. There are different kinds of worthiness depending on the kind of attempt. Perhaps moral worthiness has a special normative status, but attempts to make a basket in basketball, to hit an ace in tennis, perform a trill on the piano, too, can be worthy. In each case, the worthiness makes it fitting from the relevant point of view to praise and admire the attempt. James' attempt is equally praiseworthy from the point of view of basketball whether the ball is obstructed by the bird or not. A pianist's attempt to do a trill seems just as praiseworthy from the point of view of classical piano even if played in a room with poor acoustics which doesn't make it possible to achieve the desired effect.

Now, if an end has value, and an attempt leads to the attainment of this end, the attempt has instrumental value. Thus, in the rescue case, the successful rescuer's attempt is instrumentally better than the unsuccessful rescuer's attempt. However, the sort of value Sosa aims to capture in his talk of better and worse attempts isn't instrumental. ${ }^{6}$ One doesn't find in Sosa's axiology a principle to the effect that a belief is better to the extent that holding it causes the believer to have more true beliefs. Rather, I understand Sosa as discussing the sort of quality or worthiness we have been discussing. We will return below to the question of the sort of value in question. But it is not instrumental.

${ }^{6}$ See Sosa $(2010,63)$. 
Let us assume with Sosa that beliefs are attempts aimed at truth. Then they, too, will be assessable in respect of worthiness, epistemic worthiness. ${ }^{7}$ Our discussion above predicts that it is possible for a belief to have full epistemic worth despite being false. And this is confirmed by examples. If you fool me into thinking you are not in your office by closing your office door, turning out your light, sending me an email that you will not in the office that day, etc., my belief that you are not in your office seems just as worthy, understood as an attempt to get things right, as my belief would be in a similar case in which it is knowledge full well.

Let us now turn to some objections. First, in claiming that an attempt could have maximal worth despite being unsuccessful, one might worry that I mistake excusability for quality. 8 To answer this, suppose a baseball game has moved into the $16^{\text {th }}$ inning, seven beyond the normal 9 . If from exhaustion a player makes the poor choice of trying for a double play (getting two outs) when only one out is needed to end the inning, we might excuse him. We might say, "he made a bad decision but understandably - playing for five hours straight would impair anyone's judgment on the field." We do not praise the attempt; we see obvious fault in it, but we excuse it. Our assessments of LeBron James' attempt in the bird case, of the unsuccessful rescuer's attempt in the drowning child case, and of my belief in the office case are not like this. We do praise these attempts. James might well have an excuse for not sinking a basket, but he doesn't have or need an excuse for a poor attempt because his attempt wasn't poor.

A second objection concerns luck. It might seem I am denying the possibility that matters of luck - and generally factors outside an agent's control - could make a difference to the worthiness of an attempt. Let me make clear that I am not denying this. The worthiness of an attempt depends, for one thing, on the quality of the assessments that underlie it (e.g., in basketball shot selection), and it might be a matter of circumstantial luck that the agent is able to make such high-quality assessments. For example, Jill might have taken piano lessons, thanks to a middleclass upbringing, and might therefore positioned to make better musical assessments than someone else, Jack, who was self-taught. Moreover, the aim behind the attempt might matter. If the aim is to miss a basket, flub a trill, etc. then perhaps the attempt is made worse by success in attaining it, worse still by apt success and worst by fully apt success - where these evaluations are of course made from the perspective of the relevant practices (basketball, classical piano). In the case of morality, we might wish to say that an attempt which succeeds in its aim of murder is worse than one that does not. This accords with our (alleged) intuitions about murder and attempted murder. I take no stand on these matters. What I am

${ }^{7}$ Kant himself presumably would not join us in generalizing his claims about moral worth beyond the realm of morality. But, as our examples show, this restriction is implausible. More carefully, although there no doubt are differences in the normative standing of morally worthy actions vs. epistemic worthiness, let alone basketball worthiness, there is a common thread here. Thanks to Robert Johnson for discussion.

${ }^{8}$ I thank a referee for raising this objection. 
saying is this: bad resultant luck - bad luck in how attempts turn out - is compatible with maximal worthiness.

A third objection - really more of a challenge than an objection - appeals to Sosa's own account of the nature of performance value in Knowing Full Well. Given Sosa's account of the nature of this value - so it is claimed - his axiological principles must be true. So, I must either refute that account, or give up my criticism of his axiology.

Let's look at Sosa's account of the nature of performance value. Sosa observes that the value involved in good performances is not objective or absolute value $(2011,57-8)$. There need be nothing objectively valuable about a fully apt shot in basketball, or my having a fully apt belief that the train departs at 8:30AM. The world is not better for these performances having these properties. Rather, the value involved is aim-relative. Sosa explains the relevant superiority in terms of preferences $(2011,63-4)$. If you aim at a certain end, rational coherence might demand preference of one status $\mathrm{X}$ bearing on that end over another $\mathrm{Y}$. This is what it is for that status $\mathrm{X}$ to be better than $\mathrm{Y}$, relative to the aim.

According to the objection under discussion, Sosa's account vindicates his axiological principles. Let us see if this is correct. Here again are those principles:

Any performance, conceived of as an attempt with an aim, is

(AX1): better to the extent that it attains in its aim.

(AX2): better still to the extent that it attains its aim aptly.

(AX3): and best to the extent that it is guided to aptness by an apt belief that it would be apt, i.e., to the extent that it is fully apt. ${ }^{9}$

How are these vindicated? If you make an attempt with a certain aim, rational coherence requires certain things of you. For one thing, if you aim at attaining E, rationally you must prefer attaining $E$ to failing to attain E. This seems to ground AX1. Similarly, if you aim at E, rational coherence requires you to prefer attaining $\mathrm{E}$ aptly as opposed to attaining it inaptly. This seems to ground AX2. Finally, although Sosa doesn't discuss AX3 in the relevant passage in his 2011 book, one might think the same would apply to AX3 as well: rational coherence requires someone who attempts to attain E to prefer her attempt be fully apt as opposed to apt but not fully apt. And this- it might be claimed - grounds AX3.10 One question is whether these claims about rational coherence are true. Another is whether they do in fact vindicate AX1-3. We'll look at both questions in turn.

In the case of success vs. failure, the claim about rational coherence seems plausible enough. If I aim at making a shot, rational coherence seems to require that I prefer making it to not making it. The same is less obvious in the case of success through competence vs. through luck. It is not clear that if I aim to attain E, rational coherence requires that I prefer aptly attaining $\mathrm{E}$ to states of affairs falling short of

9 Sosa $(2015,85)$ writes: "The fully desirable status for performances in general is full aptness."

${ }^{10}$ Again, qualifications are in order for attempts that run contrary to those of the practices in which the attempt is made. See note 2 . 
that. This would be required if aiming to attain $\mathrm{E}$ rationally required aiming to attain $\mathrm{E}$ aptly. But the latter aim is not a means to the former (it doesn't cause the former; it logically guarantees it), and so the "requirement" is not that of means to end. What would require it? It is unclear to me why one would be irrational to aim simply to sink a basket without caring whether one does so aptly or not. Doubts arise as well in the case of full aptness. Supposing I aim to make a basket, it is unclear why rational coherence would require me to prefer that my attempt be fully apt as opposed to merely apt (or merely successful).

But suppose these claims about rational coherence are true. Do they vindicate AX1-3? I will argue that they do not. Suppose Sosa is right that if I attempt to attain an end $\mathrm{E}$, rational coherence requires this preference ordering:

full aptness in attaining $\mathrm{E}>$ aptness in attaining $\mathrm{E}$ without full aptness in attaining $\mathrm{E}>$ inaptly attaining $\mathrm{E}>$ failure to attain $\mathrm{E}$

Such requirements tell us something about the properties I must prefer my attempt to have in order to be rationally coherent. Preferences over attempts having properties are preferences over states of affairs. Thus, the claims about rational coherence seem at most to ground axiological claims about the corresponding states of affairs. But we're interested in comparing the value or quality of the attempts themselves, not of states of affairs or facts about them. There is a gap here that needs bridging.

One could try to bridge this gap by claiming that the value or quality of an attempt is fixed by the value of such states of affairs. One could claim: attempt $A$ has whatever value it has only thanks to the value of states of affairs such as $A$ attains its aim, $A$ attains its aim aptly, $A$ attains its aim fully aptly. But this just butts up against the Kantian intuition. That intuition is not at all undermined by the observation that some of these states of affairs are better in whatever way than others. The Kantian can grant all that. The problem is that it seems that two attempts can be of equal value - each even of full worth - despite significant difference in the value of the states of affairs such as these. Grounding the value of attempts in the value of states affairs concerning what it attains and how it attains it is just putting forth a form of consequentialism about the value of attempts. Kantian intuitions strike serious blows against such consequentialism. One cannot undermine those intuitions by the explicit appeal to a consequentialist principle. ${ }^{11}$

${ }^{11}$ Consider the opening of ch. 3 (Sosa 2010):

"In what way is knowledge better than merely true belief? That is a problem posed in Plato's Meno. A belief that falls short of knowledge seems thereby inferior. It is better to know than to get it wrong, of course, and also better than to get it right by luck rather than competence."

In this passage, I think Sosa assumes a connection between the value of an attempt (a belief) and the value of states of affairs concerning what that attempt achieves it and how. 
My answer to the third objection is therefore this. Sosa's account of the nature of performance value in terms of rational coherence of preferences is in the first instance an account of the aim-relative value of states of affairs concerning attempts not of the attempts themselves. By itself, then, the account does not vindicate AX1-3. To plug the gap, one would need to appeal to a principle connecting the value of an attempt to the value of such states of affairs. But Kantian intuitions stand precisely in the way of such a principle.

But, you may ask, what sort of value is worthiness of attempts, if it not understood in a consequentialist fashion? Is it intrinsic value, i.e., value in virtue of its intrinsic properties? Or is it final value, i.e., value for its own sake? I cannot hope to resolve these questions definitively here. However, it is useful to think about why we find LeBron's bird-foiled attempt at a basket, the failed rescue of the child, and the pianist's attempted trill in the overly reverberant room all worthy. These attempts will seem worthy to those who value the relevant ends. They will be valued because the ends are valued, but not valued because those attempts in fact produced those ends. One prima facie attractive account is that worth of attempts is derivative from the value of the ends at which they aim. (The value of the ends, following Sosa, need not be assumed to be objective, but could be understood as relative to an activity.) On this account, worthiness of attempts is non-instrumental derivative value. If final value is non-derivative value, as the notion of value for its own sake suggests, this account has the consequence that the worthiness of attempts is not final value. Nor is it intrinsic value, because whether an attempt, i.e., an intentionalfollow through on a choice, is worthy depends on the grounds of that choice, and the property of having grounds of certain sorts is an extrinsic feature of a choice. ${ }^{12}$

At this point, one might ask whether Sosa would do better to drop the appeal to attempts and base his axiology around deeds, or perhaps around deed-attempt complexes, complexes that include the attempt together with an appropriate deed which leaves off from the attempt. The former option, as we saw, is ruled out, because full aptness just isn't required for full worth of deeds, as we saw with the examples from Coffman and Sylvan. Those problems don't undermine the proposal to base the axiology around deed-attempt complexes. But, intuitively, beliefs (except perhaps in rare cases) are individuated independently of whether they are true or false. (Compare: attempts are individuated independently of whether they succeed.) It makes sense to suppose in counterfactual reasoning that a person has the same belief even though it is not true. Beliefs are not reasonably conceived as deedattempt complexes. The deed-attempt complex of a belief's being true, or being apt, or being fully apt is not the belief itself; arguably, it is a state of affairs concerning the belief, i.e., the belief's having certain features.

Let me be clear about what I have argued in this section and what I have not. I have argued that Sosa's axiological principles about performances are incorrect, and that the appeal to rational coherence does not support them. I have not argued

12 For the difference between intrinsic and final value see Korsgaard (1983). For more on how value can be derivative but non-instrumental, see Hurka (2001). For an illuminating application of Hurka's ideas to epistemology, see Sylvan (forthcoming). 
that the appeal to rational coherence is hopeless as a strategy for explaining widely accepted claims such as "true belief is better than error" and "knowledge is better than true belief." Such claims, I think, are best understood as claims about the comparative values of a belief's instantiating certain properties: a belief's being true is better than its being false, a belief's being knowledge is better than its being merely true. These claims compare the value of states of affairs, not attempts. Although there are serious obstacles to some of Sosa's claims about rational coherence constraints, I regard this general approach as promising. Something else I have not argued: I have not argued that there is no place in epistemology for the idea of credit for getting it right. I agree with Sosa that a person's belief might be true in a particular case even though its truth is not creditable to the person, or is less than fully creditable to the person. And perhaps full creditability for the truth of one's belief lines up with full aptness. Still, my key point is that the quality of the epistemic attempt itself - the belief - doesn't depend on these good results occurring. In the ethical case, you might get credit for saving a drowning child while I don't, even though our attempts are equally morally worthy, because your attempt succeeded and mine failed through bad luck. I claim the same goes for the epistemic case.

\section{An Alternative?}

Sosa's axiology makes worthiness depend on success. This section explores whether there might be a better option within Sosa's general competence-theoretic framework for performances.

To see the options, we need to be clearer on how to understand competences. Sosa offers a detailed and plausible account (2015 95-106), which I rely on in what follows. A competence, for him, is a disposition to succeed when one tries. Competences have an SSS structure, seat + shape + situation. With respect to this structure, we can distinguish nested competences. Sosa considers driving competence as an example. The innermost nested competence is the competence retained even when not behind the wheel (and so not situated properly) and even while asleep (and so not in the proper shape). Having this competence implies being disposed to succeed when one tries in the proper situation and with the proper shape. Sosa calls this the S-competence, or seat competence. We can also speak of competence to drive successfully in the proper situation (e.g., behind the wheel in a well-functioning car on the road), as well as competence to drive successfully when in the proper shape (awake and alert). These are SS-competences. They require seat and either situation or shape. Finally, when all three S's are present, the agent has the complete driving competence, the SSS-competence, and so is likely enough to succeed upon trying (simpliciter). The more nested a competence is the less variable it is. The complete driving competence, the SSS-competence, is more variable than the SS-driving competences, which are more variable than the seat competence, the S-competence.

We can distinguish similar sets of nested competences in the case of competences to get it right. Consider a competence to form true visual beliefs. Given the right situation, e.g., the agent has a good view of an object, and given that the agent is in the right shape (attentive, with well-functioning eyes, etc.), the agent is 
disposed to get it right often enough when believing on the basis of visual perception. Here, too, as in the driving competence, there is an innermost competence that survives, even if the object isn't in clear view, or the agent is distracted or asleep, etc.

Within this framework, there is a clear alternative to Sosa's axiology for attempts. One could ground the axiology not in the superiority of success over failure, but with the superiority of competent attempts over incompetent ones - of adroit ones over non-adroit ones. This is the suggestion I will pursue in the remainder of this section.

A performance is adroit always with respect to one or more competences. ${ }^{13}$ Consider competent driving that results in an accident because of an invisible obstacle placed on the road. The driver's performance was certainly adroit with respect to the seat S-competence as well as with respect to the seat+shape SScompetence. But it was not adroit with respect to the seat+situation SS-competence nor the complete SSS driving competence. In the epistemic case, if we want to understand epistemic worth of a belief in terms of competent believing, we have to ask which competences matter - S, SS, or SSS.

Adroitness with respect to a complete competence - SSS - need not improve a belief's quality over adroitness with respect to certain nested competences. Suppose you and I come out of a train station in Chicago (to vary a case from Lackey (2007)). We are equally unfamiliar with Chicago. We each approach a transit worker. We ask if the person knows the way to the Palmer House Hotel. In your case, the person answers honestly; in mine dishonestly. I end up with a false belief, you with knowledge. It is intuitive to think of our attempts to get it right as equally worthy, and very highly worthy. But only one of our beliefs is adroit with respect to the complete testimonial competence in this situation, because only one of us has this complete competence. Here I assume that the honesty of one's interlocutor is a component of situation that is individuative of complete testimonial competence. ${ }^{14}$ With respect to nested competences, however, our beliefs are both adroit. Perhaps these are what matter to epistemic worth.

Our discussion of competences has over-simplified matters somewhat. There are many elements of situation that contribute to complete testimonial competence. For each of these elements, and for any subset of them, there will be a corresponding SS-competence. Thus, consider the testimonial competence that doesn't include the honesty of the interlocutor but does include, in addition to the seat competence, the feature of living in a community in which believers are generally accurate and honest about basic facts concerning their social environment. In the Chicago visitor case, our beliefs are both adroit with respect to this

13 By contrast, there is no need to relativize aptness to competences. If a performance is apt with respect to any of the competences in the nested set of competences it is apt with respect to all of them. To be apt with respect to any one of the nested competences is to be apt with respect to the complete competence.

14 There is good reason for this assumption: in the example I am not likely to get the truth by asking my interlocutor questions whereas you are. If I try to reach the truth by accepting the testimony given, I am not likely to succeed. 
competence. ${ }^{15}$ One might hope that this commonality could explain the beliefs' identical epistemic worth. Exactly how to conceive of the relevant worthdetermining competence I will leave open, but it will be a relatively stable competence, one that doesn't come and go easily, but which builds in elements of situation that are not purely internal. To say the elements are not purely internal is to say they are not elements that would be shared by an agent's brain-in-the-vat twin. I reserve the word 'adroit' in what follows for adroitness with respect to such competences.

Compare the following reply to Kant on moral worth. Consider the attempt of someone who tries to save the child by doing a little dance, which he believes, on the basis of good but misleading evidence, to be a good way to save a drowning child.16 This seems a poorer attempt than that of the normal person who attempts a rescue in a more traditional way. Actual consequences are irrelevant to an action's moral worth but - arguably - the reliability of the method employed isn't. Kant may have refuted the straightforward act-consequentialism about the value of attempts, but he didn't refute all varieties of rule-consequentialism about their value - so the claim might be.

In light of these reflections, consider an adroitness-based axiology:

An attempt with an aim is...

(1) better to the extent that it is adroit.

Next, for reasons like Sosa's reasons for thinking full aptness is better than mere aptness, we might want to add:

(2) better still to the extent it is guided to adroitness by an adroit belief that it would be adroit. ${ }^{17}$

This axiology is still incomplete. Compare the brain in a vat (BIV) and a normal embodied human. Both believe there is something red in front of them. For the normal human, there is indeed a red apple in front of her. For the BIV, there isn't.

${ }^{15}$ Adroitness for an incomplete competence is understood in terms of the likelihood of success in conditions in which the missing elements of shape and/or situation are in place. Thus, in the Chicago visitor example, my belief is adroit with respect to the nested competence because, although my interlocutor is not in fact honest, there is a high likelihood of success in conditions that include the honesty of my interlocutor. 16 Thanks to a referee for this example.

${ }^{17}$ At least two problems arise for (2). First, one might wonder whether we should we replace 'adroit' in (2) with 'apt'. This depends on what we think of cases in which an adroit belief is guided by a Gettiered but adroit belief about its adroitness. Second, if I know that I'm in an unusual situation, I might know that an adroit attempt won't succeed. In such a case, an attempt would not be worthy, even if it is adroit, and even if it is based on an adroit belief that it would be adroit. (2) likely needs supplementation by a defeat condition. I will not pursue the necessary revisions here. 
But is the BIV's attempt to reach the truth at all worthy? Clearly it has some worth. Some might argue that it is as just as worthy as the normal human's, but even if we think it isn't, it surely has some worth. (Even the dancing "rescuer's" attempt has some worth.) The adroitness-based axiology above leaves this worth unaccounted for. Recall that we have used 'adroit' as short for 'adroit with respect to relatively stable seat-situation competences that are not purely internal'. The BIV's beliefs are therefore not adroit.

The natural move, to find value in the BIV's beliefs, is to recede farther inward and add this principle:

(0) An attempt is better to the extent that it is seat-adroit, i.e., adroit with respect to a seat competence, one embedded in a complete competence to believe the truth.

The beliefs of BIV are seat-adroit.18

We now have the outlines of an adroitness-based axiology that avoids some of the problems of Sosa's own axiology. The remainder of this section raises a problem for both axiologies. The problem stems from a feature essential to the competence-theoretic framework.

As Sosa notes $(2015,99)$, dispositions to succeed upon trying when in a certain shape and situation are cheap. Consider an odd BIV - odd from our human point of view - who believes it merely seems there is a tree before her - i.e., believes this seeming is misleading - based on the perceptual seeming that there is a tree before her, and similarly for other positive perceptual seemings. This odd BIV hits the truth regularly and in so doing manifests a complete disposition to succeed (i.e., there are SSS factors, all present, which dispose the odd BIV to likely get it right when he so believes in light of his seemings). Are these beliefs knowledge? They are, according to Sosa, if the disposition is a competence. Sosa tells us that such dispositions are competences only relative to a group that takes interest in the relevant shape and situation $(2015,105)$. But suppose there is some group that takes interest in them. It isn't clear how Sosa can avoid claiming that the odd BIV manifests a complete competence to reach the truth, at least relative to this group. The odd BIV, for Sosa, achieves a kind of knowledge, relative to this group. ${ }^{19}$

Similarly, if an odd human on earth should have the seat competence embedded in the odd BIV's complete competence, then that human being's beliefs are adroit relative to that seat competence. If the adroitness-based axiology is left unchanged, it will imply that the odd human's belief is just as worthy as the normal

18 This is an axiology of attempts only, and so does not tell us about the comparative value of attempts having properties (e.g., a belief's being true vs. false, knowledge vs. mere true belief). One might combine a Sosa-style axiology for the latter with the alternative adroitness-based axiology for attempts themselves.

19 The same points can be raised about wishful thinking in the actual world. A wishful belief may be adroit with respect to a seat of a wishful thinking competence, one requiring situational factors absent in our world. Thanks to Chris Kelp for this observation. 
BIV's. This is unacceptable. The odd human's beliefs seem worthless. They are not the least bit praiseworthy as attempts to get the truth.

It seems the only way to avoid these problems is to relativize epistemic worth, and worthiness in general, to groups. This at least allows us to say that the odd human's belief - and, if we like, the odd BIV's belief, too - is unworthy relative to us; however, we would have to concede that these beliefs could well be worthy relative to other groups. I do not have an argument against this sort of relativism, but I find it hard to accept. The normal BIV and the normal human, I want to say, do not merely have worthy beliefs relative to our interests. If another group with different interests calls the normal BIV's and normal human's beliefs unworthy, I think they would be wrong. Similarly, I think that the odd human has worthless beliefs, and one might well want to say the same for the odd BIV, and that any group that claimed their beliefs are worthy would be wrong. ${ }^{20}$

What is it that the normal BIV and normal human have which the odd BIV and odd human lack? One good candidate here is a kind of fit between what is believed and what the subject has to go on. Evidentialists will explain this fit as evidential support. Perhaps there are other accounts available as well. The important thing is that this fit is lacking in our cast of odd characters. The odd characters' beliefs do not fit their experiences, apparent memories, and etc. which they have to go on. The problem for the competence-theoretic framework, I suggest, is that it lacks a concept needed to explain epistemic value: fit. ${ }^{21}$

\section{Conclusion}

I have argued that Sosa's account of the epistemic value of beliefs places too much weight on success. An attempt can be of the highest quality, have the greatest worth, despite being unsuccessful. This is consistent with the acknowledgement that success is better than failure, and that apt success is even better than success simpliciter. For, these are claims about the comparative values of state of affairs, not about the quality of the attempts themselves. I also explored the question whether it

20 If the odd BIV's beliefs are worthless relative to any group, then this is fatal to the adroitness-based axiology more broadly. It might still be argued that reliability under can enhance a belief's quality under certain conditions, e.g., when there is a relation of fit between the belief and what the BIV has to go.

${ }^{21}$ Suppose the odd human/BIV doesn't simply believe that things only seem to be certain ways but comes to have seemings that things are not those ways and believes accordingly. Wouldn't this reinstate fit while the resulting beliefs remain epistemically worthless? (Thanks to Chris Kelp here.) If the odd human/BIV enjoys the same perceptual experiences as we do, it is difficult to see how such a seeming could fit with the content of the experience as a whole. Moreover, if the seeming were due to cognitive penetration, then we might not wish to count it as part of what one fundamentally has to go on. See McGrath (2013) for an account of how an evidentialist - or more generally someone who understands justification in terms of fit with what one has to go on - can cope with the epistemic problems of cognitive penetration. 
might be possible to construct a better axiology for attempts within Sosa's general competence-theoretic framework. The most promising avenue is one that appeals to adroit attempts, i.e., competent attempts. The difficulty is that this account struggles to explain, without resorting to relativism about epistemic worth, how the brain in a vat's beliefs have epistemic worth lacked by the beliefs of an odd human who believes in ways that would be reliable in a BIV world. What seems to be missing from the competence-theoretic framework is the crucial idea of a belief's being fitting in light of what one has to go on. ${ }^{22}$

\section{Works Cited}

Coffman, E. J. (2013). “Review of Knowing Full Well," Philosophical Review 122,1: 135-139.

Conee, Earl and Richard Feldman (2004). Evidentialism. Oxford: Oxford University Press.

Hurka, Thomas (2001). Virtues, Vices and Values. Oxford: Oxford University Press.

Kant, I. (2002). Groundwork for a metaphysics of morals (edited and translated by Allen Wood). New Haven, CT: Yale University Press.

Korsgaard, Christine (1983). 'Two Distinctions in Goodness' in The Philosophical Review 92: 169-195.

Lackey, Jennifer (2007). "Why We Don't Deserve Credit for Everything We Know," Synthese 158(3): 345-61.

McGrath, Matthew (2017). Review of Judgment and Agency. The Philosophical Review 126(3): 399-404.

(2013). "Siegel on the Impact for Epistemological Internalism,"

Philosophical Studies 162(3): 723-32.

Sosa, Ernest (2015). Judgment and Agency. Oxford: Oxford University Press.

(2010). Knowing Full Well. Princeton, NJ: Prince University Press.

(2007). A Virtue Epistemology. Oxford: Oxford University Press.

${ }^{22}$ I am grateful for comments from referees for Synthese, from Robert Johnson, Keith Harris, as well as Peter Graham, Ben McCraw, Brent Madison, Mona Simion, Kurt Sylvan, Ralph Wedwood and other members of an audience at the Bled Conference in Epistemology 2017. Special thanks go to Chris Kelp for a trenchant set of comments that led me to make major changes, hopefully for the better. 
Sylvan, Kurt (this issue). "Can Performance Epistemology Explain Epistemic Value?" Synthese this issue. 